\title{
Posconflicto colombiano y sus efectos económicos ${ }^{*}$
}

\section{Colombian post-conflict}

and its economic effects

\author{
María Isabel Ruiz Díaz** \\ John Sebastián Galeano Raquejo*** \\ Edwin Oswaldo Gil Mateus****
}

Recibido: 15 de abril de 2015

Revisado: 10 de mayo de 2015

Aprobado: 2 de febrero de 2016

\section{Resumen}

Las negociaciones de paz del Gobierno colombiano con las denominadas Fuerzas Armadas Revolucionarias de Colombia (FARC) podrían tener efectos sobre la economía colombiana. Por ello se esbozan tres escenarios - pesimista, neutral y optimista- en los que se distingan sus efectos en el ámbito financiero y de comercio internacional en los cinco años posteriores a la finalización del proceso de negociación. Partiendo del estudio de caso en cinco países que enfrentaron la terminación de un conflicto interno, ya fuera por vía militar o diplomática, se analizan variables sobre las cuales se podría prever un

* Este artículo es el producto principal de la investigación titulada El Posconflicto y los posibles escenarios financieros y de comercio internacional en Colombia, desarrollado en la Facultad de Ciencias Económicas y Sociales de la Universidad de La Salle. Cómo citar este artículo: Ruiz, M. I., Galeano, J. S. \& Gil, E. O. (2015). Posconflicto colombiano y sus efectos económicos. Revista CIFE, 17(27), 23-54

** Profesional en Finanzas y Comercio Internacional, Universidad de La Salle.

*** Profesional en Finanzas y Comercio Internacional, Universidad de La Salle.

*****Docente e investigador de la Facultad de Ciencias Económicas y Sociales de la Universidad de La Salle. Comentarios al correo electrónico edwingil@unisalle.edu.co 
efecto teniendo en cuenta el posconflicto y el desenlace de las negociaciones de paz entre la guerrilla y el gobierno. Se concluye que la balanza de bienes y servicios crecería entre el 3 y $6 \%$ en los cinco años posteriores a la firma del acuerdo; el comercio lo haría entre 10 y $15 \%$; el riesgo país se incrementaría alrededor de 4 puntos; la inversión extranjera directa (IED) aumentaría entre 40 y $50 \%$; el crecimiento del PIB anual estaría 1 o 2 puntos porcentuales por encima del actual y el gasto militar disminuiría al $10 \%$ como porcentaje del PIB.

Palabras clave: Perspectivas económicas, negociaciones.

Clasificación JEL: E66; F51.

\section{Abstract}

The government peace negotiations with the so-called Revolutionary Armed Forces of Colombia (FARC) could have an impact on the Colombian economy, being relevant to analyze such effects. Therefore, three possible scenarios to financial and international trade level for a period of five years, compared to the possible outcomes of the negotiation process are outlined. From case studies in five countries faced the completion of an internal conflict, military or diplomatic channels, variables were analyzed on which could provide an effect, taking into account the post-conflict and outcome of peace negotiations between the guerrillas and the government. It is concluded that in the five years after signing the agreement, the balance of goods and services would grow between $3 \%$ and $6 \%$; would trade between $10 \%$ and $15 \%$ greater; country risk would rise about 4 points; Foreign Direct Investment (FDI) would increase between $40 \%$ and $50 \%$; annual GDP growth would be 1 or 2 percentage points higher than the current and military spending would decrease $10 \%$ as a percentage of GDP.

Palabras clave: Economic Outlook, negotiations.

Glasificación JEL: E66; F51. 


\section{Introduction}

El conflicto armado en Colombia ha sido un problema social y económico significativo para el país. De 1958 a la fecha, ha registrado más de 220000 muertes (CNMH, 2013), cifra equivalente a la suma de habitantes de ciudades como San Andrés, La Dorada y Acacías (DANE, 2015). Los costos económicos de esta problemática son significativos; por ejemplo, para el periodo comprendido entre los años 1999 y 2003, las pérdidas económicas para el producto interno bruto (en adelante PIB) agropecuario fueron del $10 \%$ en 2003, derivadas del robo de ganado y la extorsión, sin contar los daños hechos a la infraestructura (Fedesarrollo, 2014). Como consecuencia, es posible afirmar que un país en conflicto interno sufre una desaceleración de aproximadamente 4 puntos porcentuales en su crecimiento económico. También se afirma que el gasto militar como porcentaje del PIB puede ser hasta diez veces mayor en comparación con países que no presentan conflictos internos (Collier, 1999). Para el caso colombiano, este presupuesto en el periodo 2011-2014 ha estado alrededor de 3.1 \% del PIB (Banco Mundial, 2015), por lo que el gobierno ha intentado en distintas ocasiones establecer negociaciones con los grupos armados ilegales debido a las pérdidas económicas, ambientales y humanas que este conflicto genera.

Previa a la actual negociación de paz, en el mandato del presidente Andrés Pastrana se llevó a cabo la primera mesa de negociación frente a las denominadas Fuerzas Armadas Revolucionarias de Colombia (en adelante FARG), la cual presentó una ruptura el 20 de febrero de 2002 y dejó como consecuencias positivas la disminución del porcentaje del gasto militar en un 3.16 \% del PIB durante la negociación, al pasar de $36.14 \%$ de gasto militar del PIB del año 1999 a un gasto de 32.98 \% del PIB en 2002. Del mismo modo, la inversión extranjera directa (en adelante IED) también tuvo un cambio positivo en ese periodo al aumentar en $0.43 \%$ del PIB. Por otro lado, la consecuencia negativa fue la disminución del comercio en un 3.15\% del PIB. Después del Gobierno de Andrés Pastrana, Álvaro Uribe Vélez asumió la presidencia y tuvo como estrategia la seguridad nacional, para la cual fortaleció el Ejército con el fin de cumplir la meta de una derrota militar de la guerrilla, lo cual incrementó el gasto militar en casi el doble del presupuesto en comparación con el mandato anterior. Aunque el resultado en cuanto a gasto se vio afectado tras el aumento aproximado de $0.025 \%$ del gasto militar, la percepción de seguridad se incrementó y se proyectó en el aumento de variables como el PIB, el comercio y la IED durante los dos Gobiernos de Uribe (2002-2010) (Arias, Camacho, Ibáñez, Mejía y Rodríguez, 2014).

El actual proceso de paz, desarrollado en el Gobierno de Juan Manuel Santos, se ha caracterizado por enfocarse en los aspectos económicos y sociales del país. Según el presidente Santos, los diálogos tienen como fin lograr una transformación social en la población colombiana, de manera que por medio del diálogo se disminuya la intensidad 
del conflicto y se pueda reducir el presupuesto de defensa. Teniendo en cuenta una agenda específica establecida con el ánimo de puntualizar los ciclos de negociación, estas negociaciones se llevan a cabo en el extranjero para no despejar militarmente porciones del territorio colombiano. Se decidió también no parar las operaciones militares y se estableció que la negociación debía realizarse bajo el principio de que "nada está acordado hasta que todo esté acordado" (Mesa de Conversaciones, 2016).

Lo anterior ha generado un cambio marginal en el gasto militar, que disminuyó en $0.112 \%$; en lo que concierne a la IED, esta aumentó en $0.167 \%$ durante el año 2013, pero aún se mantiene la incertidumbre en medio de las negociaciones de paz debido a que todavía no se saben los posibles efectos en seguridad, productividad y desarrollo que se producirán en las inversiones privadas de las empresas de los sectores productivos del país, así como incertidumbre en los inversionistas extranjeros existentes y potenciales.

Por ello, en este documento se efectúa un ejercicio de prospectiva en el que se evalúa la construcción de escenarios de desenlace del proceso de paz, ejercicio en el que se analiza el posible comportamiento de variables sobre flujos financieros y comerciales. Con este propósito, este documento está estructurado en cinco secciones, además de esta introducción. En primer lugar, se presenta una aproximación al concepto de posconflicto y se describen algunas teorías acerca de la relación entre paz y sus efectos positivos en la economía. En la segunda sección se describe la metodología empleada en la exploración de prospectiva. La tercera parte describe la información de cinco países de referencia y se contrastan los datos obtenidos con las teorías, esto con el fin de sustentar su aplicación en el actual proceso de paz. En la cuarta sección, a partir de la información obtenida de fuentes secundarias, se construyen los escenarios, los cuales fueron validados con un grupo heterogéneo de expertos con el fin de contrastar la opinión, punto de vista y perspectiva desde su área de conocimiento. Por último, se presentan las conclusiones a manera de reflexión.

\section{Elementos teóricos y conceptuales}

En esta sección se establecen los lineamientos teóricos y conceptuales sobre los cuales se fundamenta el modelo de prospectiva. Se presenta una aproximación al concepto de posconflicto y las teorías sobre el efecto de conflictos bélicos sobre la economía, además de considerar variables económicas, sociales y culturales de los países teniendo en cuenta su evidente interdependencia.

\subsection{Posconflicto}

Varios autores difieren acerca del concepto de posconflicto y el momento específico en el que se afirma que un país está en tal situación. Por ejemplo, el posconflicto puede ser el periodo que sigue luego de una superación total o parcial de conflictos armados o una 
disminución de ataques, secuestros, etc., en el cual no se considera el conflicto como activo (Universidad del Rosario, 2015).

También se considera que un país está en posconflicto cuando el número de homicidios disminuye a causa del conflicto por debajo de un número determinado; en ese momento, se habla de la construcción de paz, se pretende fortalecerla con el fin de evitar que el conflicto surja de nuevo. Es posible hablar de posconflicto incluso si no existe una construcción de paz, en especial en zonas donde se han debilitado los actos bélicos por parte de las organizaciones terroristas (Ugarriza, 2013).

Brahimi (2007) señala que la existencia de un escenario de posconflicto está supeditada a la ausencia de guerra; no necesariamente es paz absoluta. En este sentido, se afirma que el posconflicto no denota un término total de actos terroristas, sino su disminución, que da una ventana de expectativa para lograr la paz total (Tzifakis, 2006).

Para efectos de este documento, el posconflicto es un escenario en el cual los actos bélicos por parte de los grupos armados ilegales disminuyen en comparación con sus actos terroristas hechos en años anteriores, sin necesidad de señalar que hay una paz total. Esto es coherente con las experiencias de los países que fueron tenidos en cuenta para el ejercicio comparativo.

\subsection{Guerra, paz y efectos económicos}

La relación entre la paz y las variables económicas de una nación es un tema que ha inquietado a los economistas a lo largo de la historia. Desde principios del siglo XX, Keynes (1919) analizó esta problemática a partir de la terminación de la Primera Guerra Mundial. Entonces él presentó algunas críticas hacia la conferencia de paz celebrada en París, conocida como Tratado de Versalles. Keynes predijo el escenario en el cual Alemania, bajo las excesivas medidas impuestas por los demás miembros del continente europeo, en especial Francia, no quedaría conforme e incubaría la posibilidad de un conflicto posterior. Si se hubieran considerado los planteamientos de Keynes, como una indemnización asequible para Alemania y una política de libre cambio sin imposición de aranceles, la Segunda Guerra Mundial probablemente se hubiera podido evitar. Herbst (1990) afirma que las guerras internacionales tienden a fortalecer el Estado; por el contrario, las guerras civiles internas tienden a debilitarlo, por lo que es sensato profundizar en estas últimas y sus consecuencias económicas, las cuales son pertinentes para el caso colombiano.

Justino (2010) analiza las consecuencias de las guerras civiles sobre la pobreza a partir de los conflictos violentos durante la guerra fría. En general, estos conflictos se presentaron en países con bajos ingresos, con instituciones gubernamentales débiles que no hacían presencia en todo el territorio, en donde sus relieves físicos, conformados por montañas 
y selvas, jugaron un papel fundamental, puesto que facilitaron la estrategia de guerra de guerrillas. Según el autor, las guerras civiles afectan en gran medida a la población del Estado que las padece, por lo que este tipo de conflictos se identifica como una de las principales causas de la duración de la pobreza alrededor del mundo.

Collier (1999) destaca que las guerras civiles son más perjudiciales para un país en comparación con las guerras internacionales debido a que se producen en todo el territorio nacional. El autor propuso su teoría con base en el Modelo de Knight, Loayza y Villanueva (1996), quienes utilizaron un grupo de 79 países con variables como el crecimiento del PIB per cápita anual, el gasto militar, el número de meses de la preguerra y el número de meses de la posguerra, entre los años 1969-1989.

Adicionalmente, Collier (1999) afirma que la economía de un país tiende a beneficiarse más en un escenario de paz que en un escenario con guerras internas, midiendo el fenómeno por medio del PIB y su composición en la economía. Resalta que existen cuatro maneras en las que una guerra civil puede afectar a la economía: la primera es mediante la destrucción de recursos humanos y físicos, como la población asesinada que disminuye la fuerza laboral, además de la infraestructura destruida, como puentes, carreteras y edificaciones en general; la segunda es por medio de la ruptura del orden social, por lo que la inseguridad urbana, rural y vial aumenta y, en consecuencia, también se incrementan los costos de transacción por pérdida de confianza en las instituciones formales e informales; el tercer efecto expuesto es la desviación del gasto público, el cual hace más grande la proporción de este en rubros como seguridad por medio del fortalecimiento del ejército y la policía; en el último factor está la sustitución de portafolio, en la que los agentes privados sacan del país sus activos - humanos y financieros- para que puedan ser reinvertidos en países con riesgos menores.

Finalmente, Collier (1999) concluye que la economía de un país tiende a beneficiarse más en un escenario de paz en comparación con un escenario donde se presenten guerras civiles debido a que, de acuerdo con su modelo, el PIB per cápita anual disminuye $2.2 \%$ en comparación con el de los países que no tienen este tipo de problemas sociales. Este comportamiento es derivado de dos maneras: la primera, debido a que la guerra reduce directamente la producción; y la segunda es que se reduce el capital social por medio de la destrucción, desorganización, desviación y sustitución del portafolio, las cuales afectan de manera diferente a los sectores de la economía. Desde luego, los sectores más afectados por esta problemática social son los sectores intensivos en capital, en los cuales se encuentran la manufactura, la construcción y el transporte.

Intriligator (1996) enuncia la importancia del fin de un conflicto armado y menciona el aspecto teórico del dividendo de la paz como un beneficio derivado de un gasto menor en defensa transferido a otros propósitos económicos con el fin de beneficiar la producción civil. En el corto plazo, al momento del fin de la guerra civil, el costo económico 
aumenta, ya que hay desempleo de los recursos antes involucrados en el conflicto. Sin embargo, estos recursos son absorbidos por otros sectores con el fin de producir bienes para el resto de la sociedad civil de manera legal, lo cual se presenta en el largo plazo, por lo que, en el agregado, la sociedad se beneficia. No es necesario transferir fondos de un sector a otro como lo dicen algunos políticos, sino que es un asunto de cambiar la mezcla armas vs. alimentos con el fin de hacer una transición del sector militar al sector productivo de forma eficiente.

Brauer y Marlin (2009) calcularon un caso hipotético para el año 2007, en el cual no habría guerras en el mundo. Para este caso, el PIB hubiera sido un 13.1 \% mayor que el realmente presentado ese año. A su vez, los autores categorizaron el dividendo de la paz en dos partes. La primera es "la paz dinámica", que es el rendimiento económico obtenido por la liberación de recursos como capital, físicos y, los más importantes, los recursos humanos; las pérdidas por carecer de este tipo de paz ascienden a los 4.8 billones de dólares estadounidenses. La segunda parte, según los autores, es "la paz estática", bajo la cual estimaron las pérdidas mundiales. Este tipo de paz consiste en transferir de la producción de industrias bélicas a otras industrias mucho más productivas para la sociedad; la pérdida para el mundo con este tipo de problemática asciende a más de 2 billones de dólares estadounidenses.

De igual modo, para 2010 se realizó un estudio sobre el dividendo de la paz y se concluyó que cada año se podría aumentar el doble del crecimiento del PIB mundial si no hubiera guerras en el mundo. Se destaca que la pérdida por el dividendo de la paz en el mundo no es recuperable. Desde un punto de vista empresarial, los países con ingresos más altos y guerras internas tienen, en términos absolutos, mayores ganancias por el dividendo de la paz, lo que los hace más atractivos para las multinacionales (Schippa, 2010).

La pérdida por la violencia para el mundo, en términos generales, en cuatro años (20062009) pudo haber sido de alrededor de 28 billones de dólares estadounidenses si el $100 \%$ de guerras hubiera terminado. En un escenario más realista, si solo desapareciera el $25 \%$ de la violencia respecto a las guerras internas en el mundo, este tendría 1.75 billones de dólares estadounidenses más, los cuales podrían ser utilizados en programas para la comunidad o en un sistema productivo que al final beneficiara a la sociedad en su conjunto. La pérdida por la presencia de las guerras internas en el mundo representa el valor de las economías, en conjunto, de países como Indonesia, India, Brasil y Rusia para el año 2010 (Ibíd.).

En la figura 1, en el caso hipotético de dos países con igual PIB per cápita, uno de ellos en guerra interna, el país con el problema social (país A) llegaría a crecer anualmente 2 puntos porcentuales menos que su país vecino (país B); si la guerra persistiera a lo largo de 35 años, el PIB per cápita del país B que no presenta una guerra interna podría ser 
dos veces mayor a su contraparte, que 35 años antes tenía el mismo valor del PIB per cápita (Ibíd.).

Figura 1. Pérdida por el conflicto, representada en PIB per cápita

\section{Pérdida por el conflicto, representada en PIB per cápita}

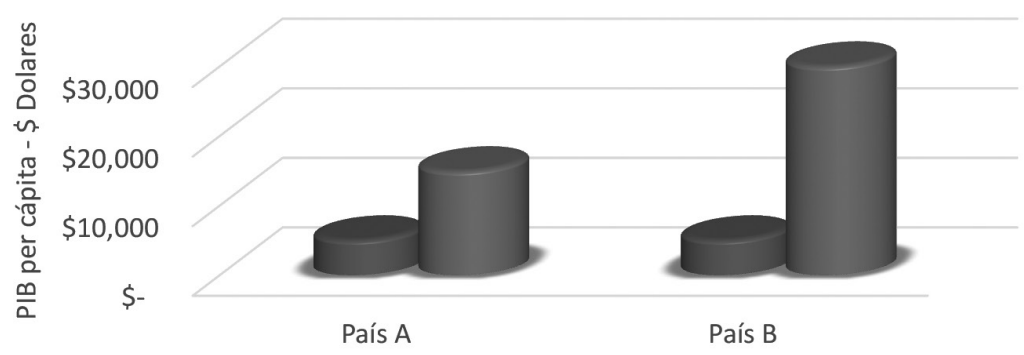

Fuente: Elaboración propia con base en (Schippa, 2010).

El dividendo de la paz no se obtiene por el simple hecho de cambiar fondos de la actividad de defensa del país a otra rama de desarrollo, sino que esta transformación del gasto en defensa incluye un cambio de trabajo, capital y demás recursos destinados hacia la defensa de un país a un rubro dedicado hacia la actividad civil. En el caso de armas vs. alimentos, un aumento del gasto en defensa es contradictorio hacia el crecimiento económico de una nación (Guaresma y Reitschuler, 2003). Esto se representa por medio de coordenadas Y (armas) y X (alimentos), de manera muy similar al argumento de fronteras de posibilidades de producción (ver figura 2).

Figura 2. Relación de inversión entre armas vs. alimentos

\section{Relación de inversión vs Armas}

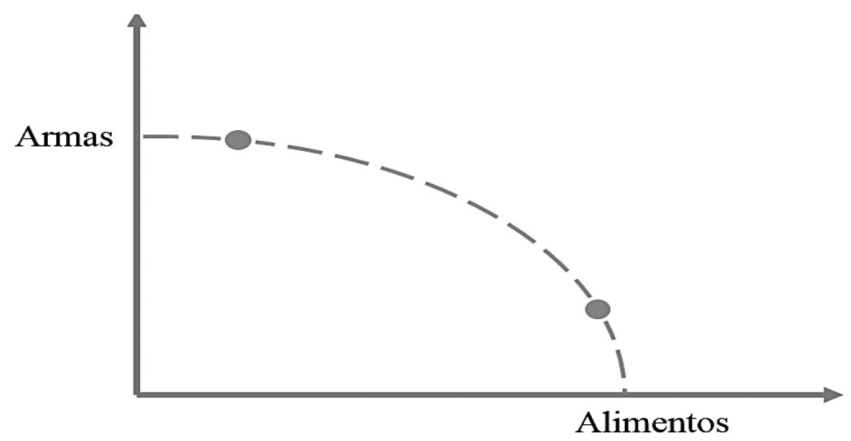

Fuente. Elaboración propia con base a Harrison (2010). 
Respecto a la relación entre inversión extranjera y conflictos armados, los extranjeros se ven atraídos a invertir en los países donde el riesgo de insolvencia sea menor, para ello se estableció un riesgo medido para cada país con el fin de determinar la seguridad de la inversión. Este riesgo es denominado "riesgo país", el cual analiza aspectos económicos, sociales y políticos dentro de los cuales se estudian varios factores, tales como la estructura y la estabilidad social y política de un país (Tagle, Checa y Sala, 2008). Este último factor considera los problemas sociales que pueden afectar la inversión, como la situación de conflicto interno en Colombia.

Con el fin de medir el "riesgo país" de un modo teórico a uno práctico, la firma internacional fP Morgan Chase emite un índice denominado Emerging Markets Bond Index (EMBI), el cual analiza este tipo de riesgo en mercados emergentes. Básicamente, se mide el riesgo que tiene un país de no cumplir sus deudas; la calificación empeora cuando aumenta el riesgo por tres razones principales, que son de tipo económico, político y social. Además, se analiza un riesgo denominado "genérico", el cual se presenta cuando el sector privado incumple sus deudas a raíz de las tres razones mencionadas anteriormente (Vela, 2011).

JP Morgan Chase no es la única entidad que emite calificaciones de riesgo, existen varias entidades encargadas de valorar el "riesgo país", como es el caso del "riesgo país EIU" (Economist Intelligence Unit), hecho por el grupo The Economist, por medio de su unidad de inteligencia. Esta institución se encarga de comparar y medir el riesgo crediticio de diferentes países del mundo. El modelo utilizado para medir el riesgo país por la entidad mencionada fue hecho en 1997 con el fin de ayudar a los inversionistas a tomar decisiones con base en datos comparados de los 128 países estudiados, desarrollados y en vías de desarrollo (The Economist Intelligence Unit, 2014).

El riesgo país EIU usa indicadores cualitativos y cuantitativos, cubre seis categorías esenciales, a saber: 1) el riesgo soberano, medido por el peligro que tiene el país de incumplir sus deudas a los acreedores por su soberanía; 2) el riesgo monetario, medido de acuerdo con el riesgo de una devaluación severa frente a monedas de referencia como el euro o el dólar estadounidense; 3) el riesgo del sector bancario, medido frente al apuro de insolvencia del mismo sector ante los depositantes o acreedores; 4) el riesgo político, en el cual se evalúa la estabilidad política del país para saber el compromiso de este para cumplir con sus obligaciones y la no afectación del mercado monetario; 5) el riesgo de la estructura económica, que no es más que el análisis de las variables macroeconómicas de la nación estudiada; 6) finalmente, se evalúa el riesgo general del país, el cual es tomado por el promedio de los puntajes de los riesgos sector bancario, monetario y el soberano (Ibíd.).

Con el fin de analizar el grado de confianza percibido por los inversionistas, se utilizará el riesgo país EIU, ya que analiza riesgos más puntuales como los mencionados 
anteriormente y considera los países guías seleccionados para la metodología explicada más adelante.

Tabla 1. Síntesis de las teorías

\begin{tabular}{|c|c|c|c|}
\hline Teorías & Autor(es) & Argumentos expuestos & $\begin{array}{c}\text { Variables } \\
\text { consideradas }\end{array}$ \\
\hline $\begin{array}{l}\text { Duración de } \\
\text { pobreza y } \\
\text { guerras civiles }\end{array}$ & Justino (2010) & $\begin{array}{l}\text { Los conflictos internos son una de las } \\
\text { causas principales de la duración de } \\
\text { la pobreza en el mundo. }\end{array}$ & $\begin{array}{l}\text { Cálculo del PIB } \\
\text { anual }\end{array}$ \\
\hline $\begin{array}{l}\text { Beneficio } \\
\text { económico en } \\
\text { escenarios de } \\
\text { paz }\end{array}$ & $\begin{array}{l}\text { Collier (1999) } \\
\text { Knight, Loayza y } \\
\text { Villanueva (1996) }\end{array}$ & $\begin{array}{l}\text { Una guerra civil afecta a la economía } \\
\text { por medio de la destrucción, } \\
\text { desorganización, desviación y } \\
\text { sustitución del portafolio. La } \\
\text { composición del PIB es afectada, así } \\
\text { como la variable en sí. }\end{array}$ & $\begin{array}{l}\text { Número de años de } \\
\text { la guerra, balanza } \\
\text { comercial de bienes y } \\
\text { servicios (porcentaje } \\
\text { PIB), comercio } \% \\
\text { PIB) e IED } \% \text { PIB). }\end{array}$ \\
\hline $\begin{array}{l}\text { Dividendo } \\
\text { para la paz }\end{array}$ & $\begin{array}{l}\text { Intriligator }(1996) \\
\text { Brauer y Marlin } \\
(2009)\end{array}$ & $\begin{array}{l}\text { Beneficio derivado de un gasto } \\
\text { menor en defensa transferido a otros } \\
\text { propósitos sociales. Sin guerras en el } \\
\text { mundo, el PIB mundial hubiera sido } \\
13.1 \% \text { en } 2007 \text {. }\end{array}$ & $\begin{array}{l}\text { Crecimiento del PIB } \\
\text { y gasto militar. }\end{array}$ \\
\hline Riesgo país & $\begin{array}{l}\text { Tagle, Checa y } \\
\text { Sala (2008) } \\
\text { The Economist Group } \\
\text { (2014) }\end{array}$ & $\begin{array}{l}\text { Analiza factores económicos, sociales } \\
\text { (conflictos internos) y políticos } \\
\text { para determinar la seguridad en la } \\
\text { inversión de un país. }\end{array}$ & $\begin{array}{l}\text { Riesgo país EIU } \\
\text { (Economist Intelligence } \\
\text { Unit). }\end{array}$ \\
\hline
\end{tabular}

Fuente: Elaboración propia con base en teorías presentadas.

\section{Datos y metodología}

En primer lugar, se eligieron dos grupos de países, el primero compuesto por tres países acordes con un escenario optimista (tabla 2) y otro compuesto por dos países que se ajustan a lo que se denomina el escenario pesimista (tabla 3).

En la selección de los países que servirán como referente en la construcción de los escenarios, se tuvieron en cuenta los siguientes criterios:

i. El proceso de paz se entabló entre el Gobierno local y una guerrilla interna.

ii. Que tuviera más de veinte años en conflicto con dicha guerrilla.

iii. Que fueran países que hayan pasado por alguno de los dos escenarios:

- El escenario optimista o apuesta, en el cual hubo un acuerdo exitoso entre la guerrilla y el gobierno, contemplando de esta forma un posconflicto estable, beneficioso para los flujos financieros y de comercio internacional. 
- $\quad$ El escenario pesimista, en el que no se llegó a un acuerdo exitoso entre la guerrilla y el gobierno, pero se consiguió llegar a un posconflicto derrotando a la guerrilla por la vía militar.

Tabla 2. Países en escenario optimista

\begin{tabular}{|c|c|c|c|c|}
\hline País & \multicolumn{2}{|c|}{$\begin{array}{l}\text { Duración del proceso } \\
\text { de paz }\end{array}$} & \multicolumn{2}{|c|}{$\begin{array}{l}\text { Fecha y razones de } \\
\text { surgimiento del conflicto }\end{array}$} \\
\hline El Salvador & \multicolumn{2}{|c|}{$\begin{array}{l}\text { 1982-1992 } \\
\text { Frente Farabundo Martí para la } \\
\text { Liberación Nacional (FMLN) }\end{array}$} & \multicolumn{2}{|c|}{$\begin{array}{l}\text { El FMLN surgió en } 1970 \text {. } \\
\text { Por razones de defensa de las ideas comunistas } \\
\text { y socialismo democrático. }\end{array}$} \\
\hline Angola & \multicolumn{2}{|c|}{$\begin{array}{l}\text { 1988-2002 } \\
\text { Unión Nacional para la } \\
\text { Independencia Total de Angola } \\
\text { (UNITA) }\end{array}$} & \multicolumn{2}{|c|}{$\begin{array}{l}\text { La UNITA surgió en } 1966 \text { bajo la ideología } \\
\text { del nacionalismo africano, panafricanismo, } \\
\text { populismo, antiguamente anticolonialismo, y } \\
\text { anticomunismo. }\end{array}$} \\
\hline Guatemala & \multicolumn{2}{|c|}{$\begin{array}{l}\text { 1985-1996 } \\
\text { Unidad Revolucionaria Nacional } \\
\text { Guatemalteca (URNG) }\end{array}$} & \multicolumn{2}{|c|}{$\begin{array}{l}\text { La URNG surgió en } 1982 \text { bajo la ideología } \\
\text { del socialismo. }\end{array}$} \\
\hline \multicolumn{5}{|c|}{ Fuente: Elaboración propia con base en Fisas (2010), Oxfam International (2003), Álvarez y Pardo (2002), } \\
\hline \multicolumn{5}{|c|}{ Tabla 3. Países en escenario pesimista } \\
\hline País & $\begin{array}{l}\text { Duración del } \\
\text { conflicto }\end{array}$ & $\begin{array}{r}\text { Razones } \\
\text { de }\end{array}$ & $\begin{array}{l}\text { argimiento } \\
\text { licto }\end{array}$ & $\begin{array}{c}\text { Razones de la finalización } \\
\text { del conflicto }\end{array}$ \\
\hline Perú & $\begin{array}{l}\text { 1980-1999 } \\
\text { Sendero Luminoso }\end{array}$ & $\begin{array}{l}\text { Fundado } \\
\text { Guzmán, } \\
\text { a los privil } \\
\text { peruanas. } \\
\text { ejemplo de }\end{array}$ & $\begin{array}{l}\text { imael } \\
\text { se oponía } \\
\text { de las élites } \\
\text { o por el } \\
\text { Castro. }\end{array}$ & $\begin{array}{l}\text { Captura del máximo } \\
\text { comandante del grupo y } \\
\text { posterior división de la } \\
\text { organización. }\end{array}$ \\
\hline Sri Lanka & $\begin{array}{l}\text { 1983-2009 } \\
\text { Tigres de Liberación } \\
\text { de la Tierra Tamil } \\
\text { (LTTE) }\end{array}$ & $\begin{array}{l}\text { Discrimin } \\
\text { parte de lo } \\
\text { los tamiles }\end{array}$ & aleses hacia & $\begin{array}{l}\text { Aumento de ofensiva militar } \\
\text { y asesinato de su fundador y } \\
\text { comandantes cercanos. }\end{array}$ \\
\hline
\end{tabular}

Fuente: Elaboración propia con base en Gregory (2009), Caston (2013), Kugiel (2009), Paz (2010) y Rawat (2012).

\subsection{Variables que se van a considerar}

A partir de las teorías revisadas, se tuvieron en cuenta variables macroeconómicas y su comportamiento histórico para todos los países por analizar. Estas fueron:

- El dividendo de la paz hace uso de la variable de gasto militar. 


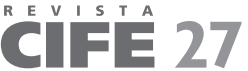

ISSN: 0124-3551 / Año 17, No 27 / julio-diciembre / pp. 23-54

- La teoría del beneficio económico en escenarios de paz hace uso de las variables balanza comercial de bienes y servicios, grado de apertura comercial y la entrada de la IED.

- La teoría del riesgo país analiza varios factores socioeconómicos importantes para los inversionistas y a partir de ellos crea el indicador que mide el riesgo de no pago de un país.

- La teoría de la duración de la pobreza debido a guerras civiles hace uso del crecimiento del PIB.

\section{Modelo de prospectiva}

Para la construcción de los escenarios para los flujos financieros y de comercio internacional en Colombia, se planteó un modelo ajustado que se divide en cuatro etapas y que se expone gráficamente en la figura 3.

Figura 3. Modelo de prospectiva propuesto

\begin{tabular}{|l|l|l|l|l|}
\hline $\begin{array}{l}\text { Estado del arte } \\
\text { y tendencias } \\
\text { mundiales }\end{array}$ & $\begin{array}{l}\text { Etapa de } \\
\text { diagnóstico }\end{array}$ & $\begin{array}{l}\text { Identificación } \\
\text { de variables } \\
\text { estratégicas } \\
\text { o clave }\end{array}$ & $\begin{array}{l}\text { Diseño y } \\
\text { evaluación de } \\
\text { escenarios }\end{array}$ \\
\hline $\begin{array}{l}\text { Información } \\
\text { secundaria, } \\
\text { antecedentes } \\
\text { de procesos de } \\
\text { posconflicto en } \\
\text { otros países. }\end{array}$ & $\begin{array}{l}\text { Análisis de } \\
\text { factores clave } \\
\text { que inciden en } \\
\text { los flujos que se } \\
\text { van a analizar. }\end{array}$ & $\begin{array}{l}\text { Realización } \\
\text { de análisis } \\
\text { estructural } \\
\text { con software } \\
\text { MiCMAC. }\end{array}$ & $\begin{array}{l}\text { Diseño con la } \\
\text { técnica Ábaco } \\
\text { de Régnier junto } \\
\text { con el apoyo } \\
\text { del método de } \\
\text { proferencia. }\end{array}$ \\
\hline
\end{tabular}

Fuente. Elaboración propia con base en Correa (2011).

Como se muestra en la figura 3, en primera instancia se realizó la etapa del estado de arte y tendencias mundiales mediante el estudio de casos múltiples.

En la segunda y tercera instancias estuvieron las etapas de diagnóstico e identificación de variables estratégicas, por lo que se utilizó el software MICMAC en la realización de la técnica de análisis estructural, además del plano cartesiano en el que se vieran la motricidad y la dependencia de las variables (Mojica, 2005), esto con el propósito de confirmar si las variables analizadas efectivamente tienen una relación estrecha con el propósito del modelo de prospectiva sugerido.

Tres escenarios se plantearán como proceso final, los cuales se abordarán mediante el uso de dos técnicas con el fin de proporcionar un análisis más amplio de cada uno de ellos. La primera técnica por aplicar es la de ejes de Peter Schwartz, en la que se utilizará 
la información secundaria ya obtenida de países guías y del comportamiento económico interno, poniendo cuatro factores en los ejes que permiten la configuración de los escenarios y el análisis (Bello-Montes, 2014). La segunda técnica por utilizar es la del Ábaco Régnier, en la cual, con la opinión de expertos, se evaluará el escenario más favorable para la economía colombiana, para luego categorizar los resultados por colores del semáforo (Correa, 2011).

\section{Casos internacionales y efectos económicos}

Para examinar la validez de las teorías en los casos específicos de países con conflictos internos terminados en consonancia con lo enunciado anteriormente, se analizaron variables como el crecimiento del PIB (\% anual), el riesgo país EIU, el porcentaje del PIB de las variables como la IED, gasto militar, balanza comercial de bienes y servicios y comercio, para los cambios en los flujos comerciales y financieros.

Los datos utilizados son de corte longitudinal, en periodos comprendidos por cinco años anteriores y cinco posteriores al punto de inflexión, el cual fue el año en el que se efectuó la firma del acuerdo de paz o el año en el que se declaró el triunfo de las Fuerzas Militares.

Posteriormente, se realizó un análisis del comportamiento de las variables sobre su incremento o disminución, según el caso en cada país, mediante un estudio de hechos estilizados dividido en dos grupos de países, el primero conformado por los países que cumplieron con el escenario positivo y el segundo por los países que cumplieron con el escenario pesimista.

\subsection{Países con escenario optimista}

Partiendo del análisis del comportamiento de las variables de los países con escenarios optimista -El Salvador, Angola y Guatemala-, se observó un impacto positivo en las variables estudiadas debido a que el ambiente económico mejoró mediante el uso de vías diplomáticas en la solución del conflicto armado.

\section{El Salvador}

El impacto que la firma de paz generó en la economía salvadoreña se muestra en la figura 4. Por un lado, respecto al crecimiento del PIB después del punto de inflexión -que en el caso del Salvador fue el año 1992, en el que se efectúo la firma de la paz- ${ }^{-}$se puede analizar que sufrió un cambio de tendencia negativa debido a una disminución constante, lo cual implicaría una desaceleración de la economía interna posiblemente bajo un supuesto de incertidumbre y factores externos. Por otro lado, se pueden visualizar los impactos positivos como la drástica disminución del porcentaje del PIB invertido en gasto militar, lo cual generó un impacto positivo debido a que ese dinero se pudo destinar a 
proyectos más productivos que la guerra, además del aumento del porcentaje del PIB en IED, posiblemente por el aumento de la confianza en la seguridad del país.

Figura 4. Participación porcentual de algunas de las variables observadas en el PIB de El Salvador
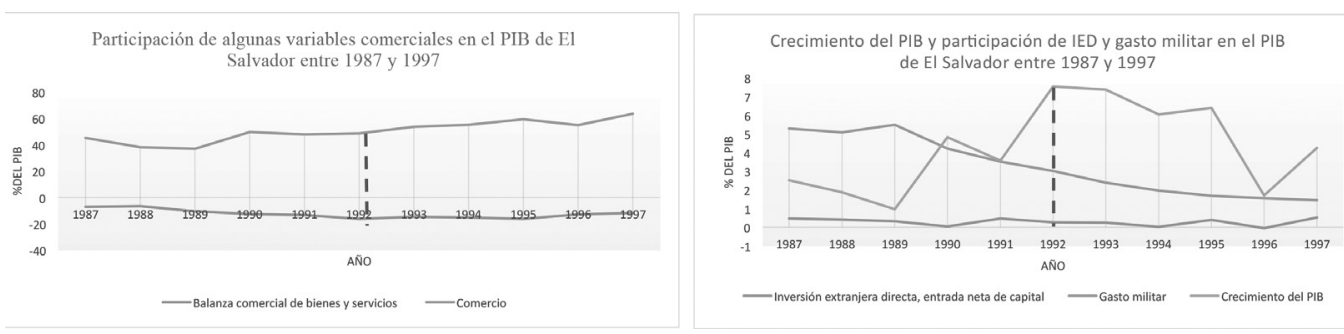

Fuente: Elaboración propia con base en datos del Banco Mundial (2015).

Respecto al flujo de comercio internacional, El Salvador presentó un aumento en las dos variables. Por un lado, la variable de comercio, como se visualiza en la figura 4, tuvo una apertura comercial más elevada a partir de la fecha de la firma de la paz, aunque manteniendo la tendencia. Y por el lado de la balanza comercial, se visualiza la recuperación a partir del punto de inflexión, solo que no tan marcada como se esperaría.

\section{Angola}

En la economía de Angola se vio un cambio marcado por el punto de inflexión, que en este caso fue el año 2002, fecha de la firma de la paz, como se observa en la figura 5, en la que variables como la IED, después de tener un comportamiento inestable, presentaron una disminución constante durante tres años consecutivos, posiblemente por una inseguridad de parte de los inversionistas por diversos factores ajenos a la inseguridad, que era una de las causas que influenciaba esta variable. Además de la IED, el incremento del PIB también tuvo un cambio de comportamiento a partir del punto de inflexión, solo que de una manera positiva y constante durante cinco años.

Figura 5. Participación porcentual de algunas de las variables observadas en el PIB de Angola
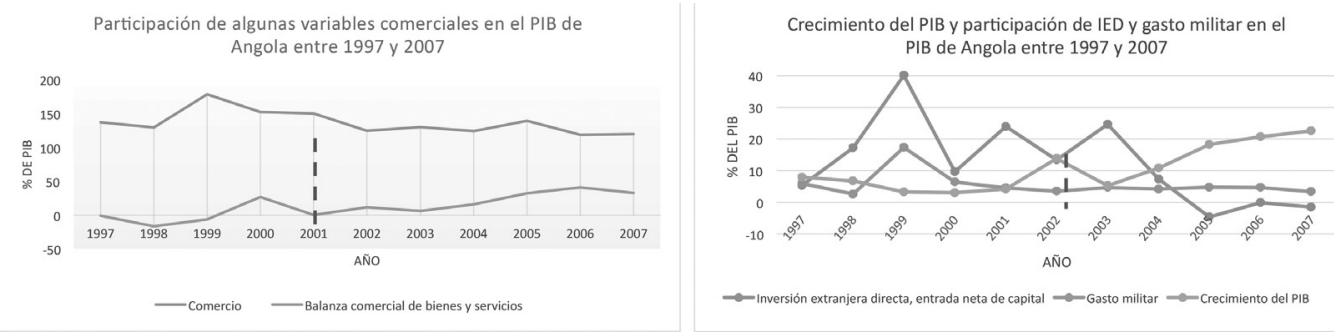

Fuente: Elaboración propia con base en datos del Banco Mundial (2015). 
Por el lado del comercio, se evidenció que la balanza comercial ya traía un comportamiento positivo desde antes del punto de inflexión y que después este mantuvo su tendencia, mientras que la variable de comercio sí presentó una caída de su porcentaje de participación en el PIB, es decir, que el grado de apertura comercial disminuyó, pero esto no fue a partir de la firma de la paz, sino que ya tenía una tendencia negativa anterior que continuó, lo que pudo ser producto de agentes externos a la negociación de la paz.

\section{Guatemala}

Durante tres años antes de la firma de paz, la economía guatemalteca tuvo una etapa de incertidumbre total en los inversionistas extranjeros, como se observa en la figura 6, en la que la IED se mantuvo casi perfectamente constante; y tras un año de haber pasado el punto de inflexión, que en este caso fue el año 1996, se registró un aumento de la confianza inversionista, reflejado en el incremento de la variable.

Figura 6. Participación porcentual de algunas de las variables observadas en el PIB de Guatemala
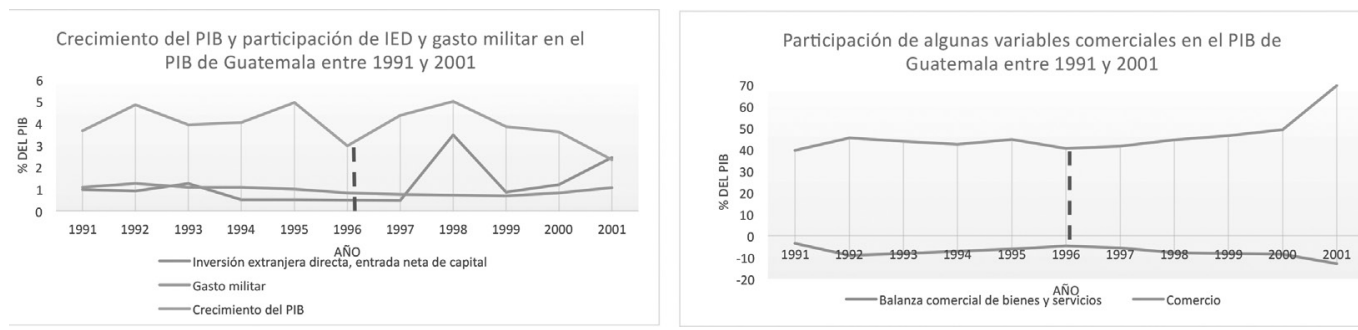

Fuente: Elaboración propia con base en datos del Banco Mundial (2015).

Otra muestra de incertidumbre sobre dicho proceso de paz efectuado en Guatemala se evidenció en el crecimiento del PIB durante el punto de inflexión, dada la desaceleración de la economía en el periodo 1995-1996, pero al año siguiente se retomó el comportamiento económico que anteriormente se presentaba tras el cumplimiento de los acuerdos de paz; esto quizás fue una desconfianza por parte del mercado interno sobre los acontecimientos políticos y el impacto que estos generarían en la economía. En cuanto al gasto militar, sí se evidenció el mismo comportamiento que en los otros países, lo cual es una disminución paulatina de esa variable, pero en el período 1999-2001 se incrementó nuevamente por factores ajenos a la guerrilla Unidad Revolucionaria Nacional Guatemalteca (URNG).

En cuanto al comportamiento comercial del país, se evidenció que, si bien el porcentaje de la balanza comercial en el PIB ya era negativo posterior a la firma de la paz, su comportamiento cambió al decrecer la variable, lo cual significó que sus importaciones 
aumentaron y la industria interna disminuyó sus exportaciones. Por otro lado, se evidenció que después de la firma de paz, el comercio incrementó paulatinamente, lo que implica que el nivel de apertura comercial sufrió un impacto positivo para la economía, quizás no tan marcado por el proceso de paz, dado su ligero cambio de tendencia.

\subsection{Países en escenario pesimista}

Respecto al análisis del comportamiento de las variables de los países en el escenario pesimista -Perú y Sri Lanka-, estas naciones registraron una mejora de sus variables económicas, que se presentó debido a la confianza en la economía que surgía desde el momento en el cual la guerra interna cesaba, pero vale la pena aclarar que el comportamiento no fue inmediato y que en algunos casos tomó más tiempo que en otros, pero, en general, se logró un aumento de las variables económicas registradas.

\section{Perú}

La economía peruana se debilitó debido a la guerra interna, hasta tal punto que entre los años 1975 y 1991, el PIB del país creció tan solo 1.78 \%, y el de la zona de Ayacucho, donde la guerrilla hacía presencia importante, este decreció en un 13.88 \% (Escárzaga, Llaque y Chamorro, 2002).

Figura 7. Participación porcentual de algunas de las variables observadas en el PIB de Perú
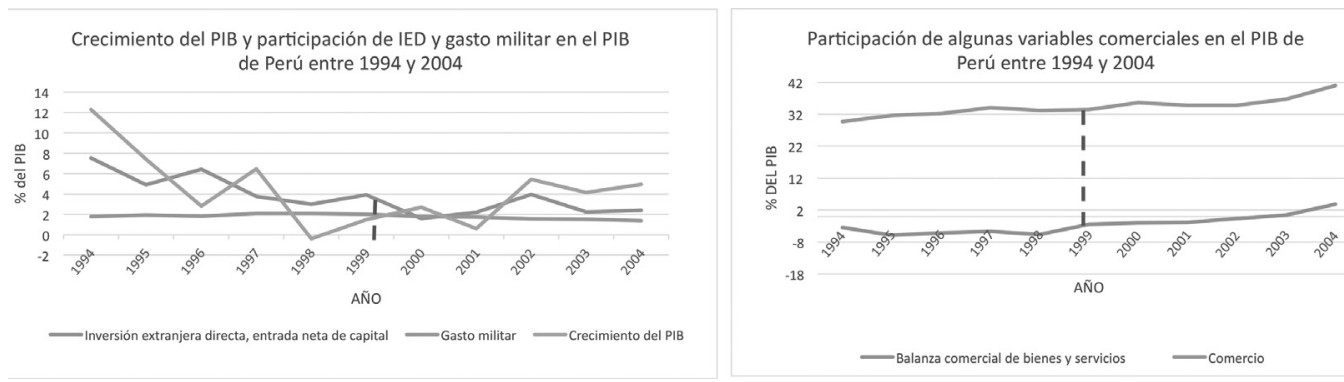

Fuente: Elaboración propia con base en datos del Banco Mundial (2015).

Aunque no hay una fecha exacta y oficial de la terminación del conflicto en Perú, este se empezó a debilitar fuertemente desde la captura del líder de Sendero Luminoso y con la posterior derrota del Movimiento Revolucionario Túpac Amaru (MRTA) a mediados de los años noventa, hasta alcanzar una época de posconflicto después del año 1999, cuando casi no se presentaba ninguna actividad terrorista en contra del Estado. Como se puede observar en la figura 7, la situación de Perú es diferente debido a que el país ha sufrido una alta incertidumbre, en particular por parte de los inversionistas, quienes temen que el conflicto se reactive dado que esta organización aún existe, pero con 
menor poder. Es por esto que después del año 1999, la IED ha bajado y luego ha vuelto al promedio, y el gasto militar se ha mantenido estable para preservar la seguridad del país y prevenir posibles conflictos; sin embargo, el crecimiento del PIB presentó una leve recuperación, pero no comparado con los cinco años anteriores al de estudio.

En la figura 7 se observa que, en los años siguientes al año de estudio, el comercio y la balanza comercial de bienes y servicios como porcentaje del PIB crecieron debido al incremento de confianza de sus ciudadanos para comercializar productos del país. A pesar de que este comportamiento no concuerda con el de la IED, se podría deducir que el comportamiento descrito anteriormente fue jalonado por las inversiones de los ciudadanos peruanos y no por los extranjeros.

\section{Sri Lanka}

Sri Lanka es un país que luego de pasar por todo un enfrentamiento armado -el cual tuvo como fin la rendición de la guerrilla interna-, económicamente tuvo unas repercusiones positivas tras el cambio del comportamiento de muchas variables, como el crecimiento del PIB. Esta variable venía creciendo de una manera importante antes del fin del conflicto, pero fue bajando debido a la decisión del gobierno de intensificar la guerra, a pesar de que la comunidad internacional no estaba de acuerdo con esa decisión.

Figura 8. Participación porcentual de algunas de las variables observadas en el PIB de Sri Lanka
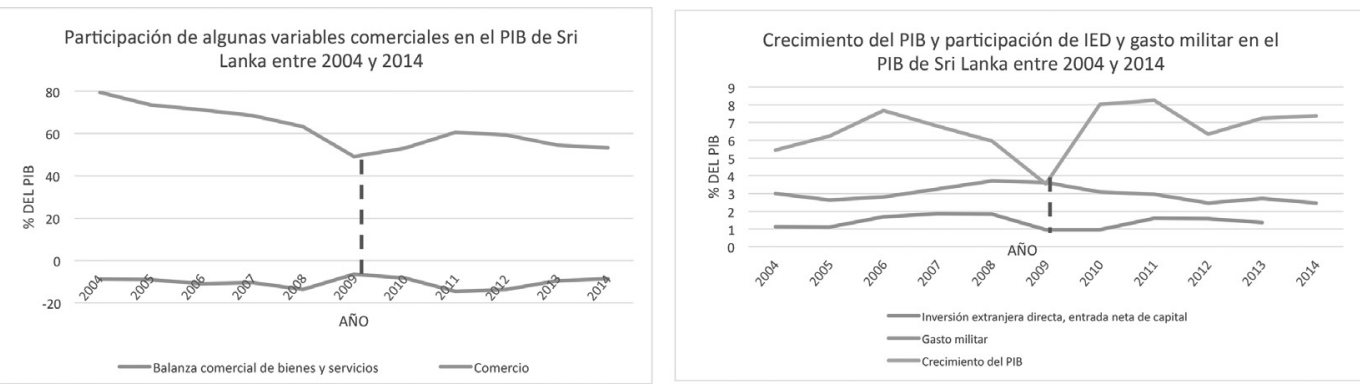

Fuente: Elaboración propia con base en datos del Banco Mundial (2015).

Como se puede observar en la figura 8, después de 2009, el crecimiento del país ha sido mayor debido al fin del conflicto. Este mayor crecimiento quizás se produjo por el cambio de la tendencia del gasto militar, la cual disminuyó después de 2009, lo que implica mayor disponibilidad del PIB para otros fines positivos para la sociedad. En cuanto a la IED, se observa el impacto de la incertidumbre para los años anteriores al punto de inflexión, debido a que el gobierno anunció que, a pesar de las presiones internacionales 
para buscar una salida al conflicto con diálogos, intensificaría las presiones militares en contra del grupo armado. Esta situación repercutió en la entrada de capitales a la economía de Sri Lanka, sin embargo, después de 2009 se ha evidenciado un incremento paulatino de esta variable, lo cual afecta el comercio y otras variables que tienen relación con la confianza de los países extranjeros.

Como anteriormente se mencionó, la variable de comercio tuvo un cambio de tendencia radical tras la victoria del ejército nacional, hecho que implicó que el país afrontara una apertura comercial positiva que impactó también en la balanza comercial, la cual ha intentado tener un comportamiento positivo, quizás incentivando las exportaciones por medio de políticas internas.

Las figuras presentadas evidencian que después de que fue conocida la decisión del gobierno de intensificar el nivel de la guerra en el año 2005, las variables económicas del país fueron empeorando, pero después del año 2009, cuando el presidente del país oficializó la derrota del grupo guerrillero, todas las variables se fueron recuperando en los cinco años siguientes.

\subsection{Contraste de las teorías y evolución de las variables}

Luego del análisis de la evolución de los flujos financieros y de comercio internacional en los países elegidos, se contrastaron los datos con las teorías, como del dividendo de la paz - entendida como el mejoramiento de los indicadores económicos-, del riesgo país, la duración de la pobreza debido a guerras civiles y el beneficio económico en escenarios de paz (Intriligator, 1996; Justino, 2010; Brauer y Marlin, 2009; Collier, 1999).

Para ello, se implementó la matriz evaluativa, diseñada con la técnica CONSENSUS, elaborada por Mojica (2008) teniendo en cuenta las modificaciones realizadas, como el cambio de las variables ubicadas en el lado superior de la matriz, cambiándolas por los países guía con el fin de ajustar a las necesidades de contraste; no obstante, se utilizó la misma calificación cualitativa empleando los siguientes códigos: $\mathrm{F}=$ fuerte, $\mathrm{D}=$ débil, $\mathrm{N}$ $=$ nulo, esto con el propósito de evaluar la influencia de las teorías respecto al comportamiento real de los países en revisión (ver tabla 4).

A partir de la desviación estándar, se evidencia que entre mayor sea la media, la probabilidad de que la teoría se cumpla será mayor. Esto arroja como resultado que las teorías aplicadas a la investigación sí se cumplen en la práctica y, por ende, será acertado establecer un marco comparativo que formará parte del proceso de creación de escenarios. 
Tabla 4. Contraste de las variables con las teorías

\begin{tabular}{|c|c|c|c|c|c|c|c|c|}
\hline Teorias / Países & $\begin{array}{l}\frac{\pi}{0} \\
\text { on } \\
\end{array}$ & 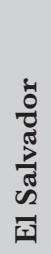 & 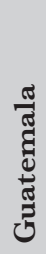 & 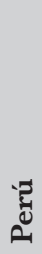 & 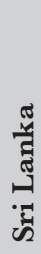 & 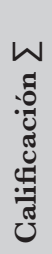 & 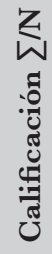 & 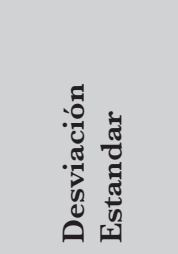 \\
\hline Dividendo de la paz & $\mathrm{D}$ & $\mathrm{N}$ & $\mathrm{N}$ & $\mathrm{N}$ & $\mathrm{D}$ & 4 & 0.8 & 2.2627417 \\
\hline Teoría del riesgo & $\mathrm{N}$ & $\mathrm{D}$ & $\mathrm{F}$ & $\mathrm{N}$ & $\mathrm{D}$ & 9 & 1.8 & 5.091168825 \\
\hline $\begin{array}{l}\text { Teoría de la duración } \\
\text { de la pobreza debido a } \\
\text { guerras civiles }\end{array}$ & $\mathrm{F}$ & $\mathrm{F}$ & $\mathrm{F}$ & $\mathrm{D}$ & $\mathrm{F}$ & 22 & 4.4 & 12.44507935 \\
\hline $\begin{array}{l}\text { Teoría de beneficio } \\
\text { económico en } \\
\text { escenarios de paz }\end{array}$ & $\mathrm{D}$ & $\mathrm{F}$ & $\mathrm{D}$ & $\mathrm{D}$ & $\mathrm{N}$ & 11 & 2.2 & 6.222539674 \\
\hline
\end{tabular}

Fuente: Diseñada con técnica CONSENSUS a partir de Mojica (2008).

\section{Escenarios de posconflicto}

En esta sección se expone el desarrollo del modelo de prospectiva propuesto, el cual permite identificar los factores clave que pueden influir en el cambio del resultado mitigando el sesgo de información. También se analizan la dependencia e influencia de las variables pertenecientes a los flujos financieros y de comercio internacional, lo cual es fundamental en la construcción de los escenarios expuestos al final de la sección.

\subsection{Análisis estructural}

Con el fin de realizar un estudio prospectivo de la situación del conflicto armado en Colombia y sus consecuencias económicas, se hizo uso del programa MICMAC para identificar las variables de mayor impacto e importancia en los flujos financieros y de comercio internacional. El software arrojó un resultado que es expuesto en la figura 9. Se empleó un total de veinte variables que han estado ligadas con el conflicto en Colombia, entre las cuales se encuentran el PIB, la IED, la esperanza de vida y el desplazamiento, entre otras. 
Figura 9. Influencia e interdependencia de las variables para un análisis estructural

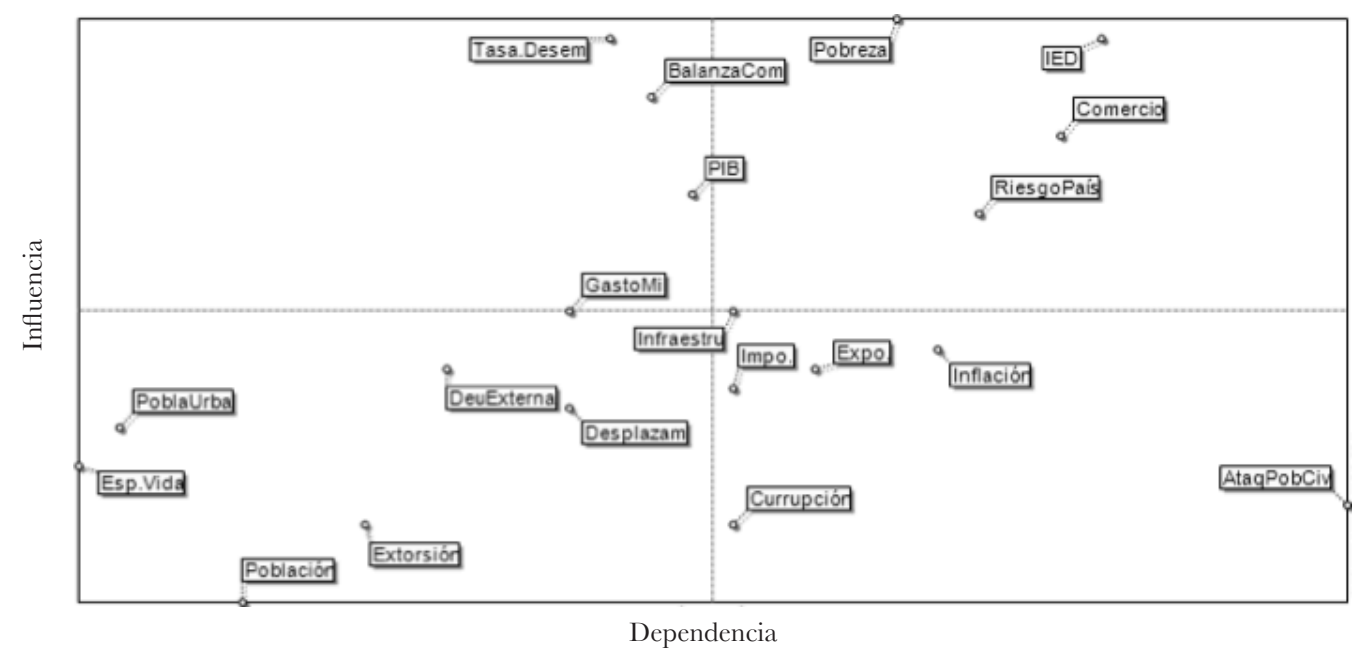

Fuente: Elaboración propia con base en el Software MICMAC.

La figura 9 es útil para analizar la relación de las variables en términos de dependencia e influencia de estas mismas con respecto al objetivo del presente estudio. Como resultado de esta interacción entre las variables -desarrollada por medio del software MICMAC-, se aprecian cuatro grandes zonas. El área superior izquierda se denomina zona de poder, puesto que en ella se encuentran variables indicadas como "ganadoras", tales como gasto militar, PIB, tasa de desempleo y balanza comercial, que gozan de gran influencia en el objetivo del estudio y que son de poca dependencia. Así mismo, en el lado superior derecho se encuentran variables tales como pobreza, IED, comercio y riesgo país, que presentan una alta dependencia e influencia; esta área se denomina zona de conflicto debido a que las variables que contiene deben ser tenidas en cuentan en un futuro porque pueden pasar a otras zonas. El área inferior de la figura es denominada zona muerta debido a que particularmente las variables que se encuentran en la zona inferior izquierda tienen menor relevancia para el objetivo de esta investigación(Villegas \& Cortez, 2011).

En conclusión, las variables que se encuentran en la parte superior de la figura 9 tienen una gran importancia para la investigación y se debe poner especial atención a su comportamiento a lo largo del proceso del posconflicto. Dado que en la investigación se analizan las variables financieras y de comercio internacional, se tendrán en cuenta la balanza comercial, el PIB, el gasto militar, la IED, crecimiento del PIB, el riesgo país y el comercio. 


\subsection{Diseño y descripción de escenarios}

La información económica e histórica de países que ya habían enfrentado escenarios iguales a los planteados en el trabajo de investigación se utilizó para el diseño de los escenarios, esto con el fin de plantear hipótesis sobre lo que podría llegar a ocurrir en los flujos financieros y de comercio internacional en Colombia. Esta información se dirigió a los empresarios y a los inversionistas nacionales y extranjeros para prever las oportunidades o los riesgos que se podrían presentar de acuerdo con las hipótesis planteadas en cada escenario.

La técnica de ejes de Peter Schwartz (ver figura 10) expone los escenarios y los elementos que se han de estudiar en cada uno de ellos.

Figura 10. Técnica de ejes de Peter Schwartz

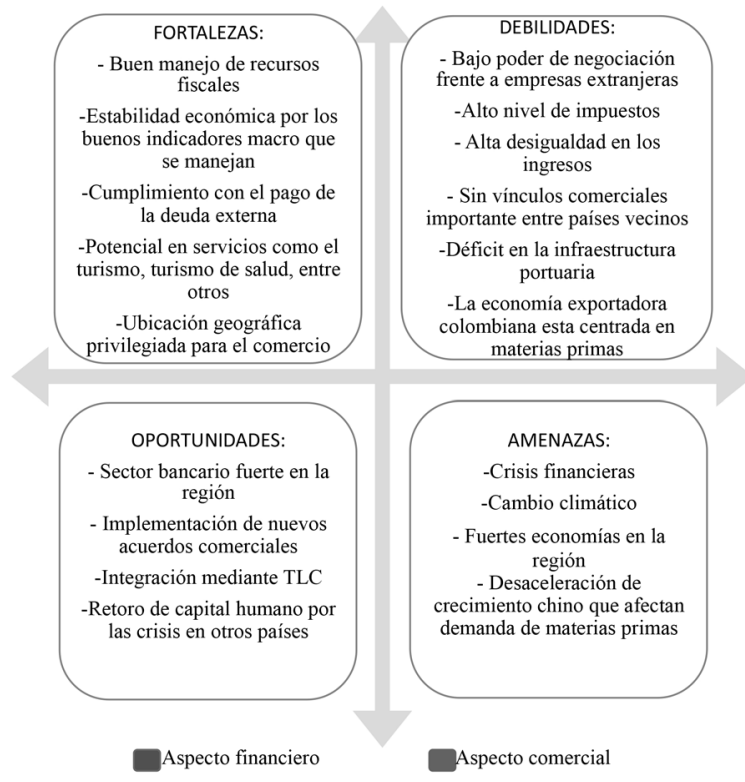

Fuente: Elaboración propia con base en Bello-Montes (2014).

Tres partes importantes se hallan en la descripción más profunda de los escenarios. La primera es la descripción de los posibles acontecimientos que caracterizarán a cada escenario. La segunda parte exhibe lo ocurrido en cada una de las variables observadas de los países guías teniendo en cuenta que se obtuvieron los promedios de los cinco años anteriores y de los cinco años posteriores para luego obtener la diferencia de estos promedios y así determinar las variaciones. En la tercera y última parte se encuentra un posible panorama que podría enfrentar Colombia en dichos escenarios de acuerdo con lo ocurrido en los países guías. 
ISSN: 0124-3551 / Año 17, No 27 / julio-diciembre / pp. 23-54

\subsubsection{Escenario optimista o apuesta}

Este escenario se contemplaría bajo un ambiente exitoso del acuerdo de paz firmado entre las FARC y el Gobierno nacional, en el que se llegaría a un común acuerdo en todos los puntos negociados, entre los que se encuentran el tema agrario, la participación política, las víctimas, las drogas ilícitas y el fin del conflicto. Esto implicaría que Colombia afrontaría un proceso de posconflicto vinculado a la desmovilización, la restitución de tierras a los campesinos, mayor participación política de los integrantes de las FARC, entre otras acciones sociales y políticas que influirán en la economía interna.

Según datos del Banco Mundial, en los tres países guías que afrontaron este escenario (Angola, El Salvador y Guatemala), se observó el comportamiento de las variables teniendo en cuenta la diferencia de los promedios cinco años antes y cinco años después del punto de inflexión que supuso la firma del acuerdo de paz en cada uno de ellos.

Los flujos de comercio internacional obtuvieron un impacto positivo, principalmente en los países de Centroamérica, como El Salvador y Guatemala, según el comportamiento de tres variables. La primera variable que muestra el efecto sobre los flujos de comercio internacional es el comercio (\% del PIB), en que países como El Salvador y Guatemala tuvieron un incremento de $27.71 \%$ y $16.37 \%$, respectivamente, mientras que en Angola fue de - $15.52 \%$. La balanza comercial de bienes y servicios (\% del PIB) aumentó en Angola y El Salvador; por el contrario, en Guatemala se obtuvo una disminución del $20 \%$. Por último, el riesgo país muestra que la imagen a nivel internacional para los inversionistas y para las empresas aumentó en los países centroamericanos en 10.40 y 4 puntos para El Salvador y Guatemala, respectivamente, según datos de The Economist, mientras que en Angola fue de -8.65 puntos.

En conclusión, los países de Centroamérica presentaron un impacto positivo mayor en los flujos de comercio internacional que el registrado en el país del continente africano, esto quizás debido a que los manejos de las economías de estos países y los niveles de afectación tras el fin de un conflicto armado son diferentes, además de la diferencia de interés que tienen los países de la comunidad internacional en estas negociaciones de paz.

Para los flujos financieros se analizó el comportamiento de tres variables. La IED, como entrada neta de capital (\% del PIB), tuvo un incremento en las economías de Centroamérica, pero en la economía angoleña disminuyó $73.16 \%$. El crecimiento del PIB después de la firma de paz solo se incrementó en Angola, mientras que en Guatemala y El Salvador tuvo un comportamiento negativo. Por último, el porcentaje del PIB destinado a gasto militar tuvo el comportamiento esperado en los cinco años posteriores a la firma de la paz en los tres países guías, ya que disminuyó $40.92 \%$ en Angola, $60.43 \%$ en El Salvador y $26.88 \%$ en Guatemala. 
De esta forma, se prevé que, en Colombia, ante la firma del acuerdo de paz se podría tener un aumento de entre el $3 \%$ y $6 \%$ de superávit en la balanza comercial, teniendo en cuenta el potencial exportador de Colombia en productos extractivos y agrícolas, como frutas exóticas, y por el bienestar económico que se ha presentado desde hace algunos años en la región. En comercio tendría un incremento de entre el 10 \% y 15 \%. Y respecto al riesgo país, Colombia afrontaría un incremento de 4 puntos o más, lo cual permitiría tener un aumento positivo en cuanto a los flujos de comercio internacional.

El panorama también sería favorable en los flujos financieros, ya que, al igual que en los países guías, se presentaría un importante aumento de la IED, de entre el 40 \% y $50 \%$, ayudado por el riesgo país, el cual aumentaría la seguridad al inversionista. El crecimiento del PIB sería de entre el $5 \%$ y $7 \%$ anual, teniendo en cuenta que la economía entraría en un bienestar no solo en las empresas, sino también en el agro y otros sectores afectados por la guerra. Por último, si ocurriera en Colombia el mismo comportamiento presentado en los países guías, se afrontaría una disminución del gasto militar aproximadamente del $40 \%$ al $50 \%$, pero, teniendo en cuenta que en Colombia existen diversos grupos al margen de la ley y que el pie de fuerza militar fue de 470988 efectivos para el año 2014, no se podría afirmar una reducción tan alta de esta variable por la firma de este único acuerdo de paz. Según lo anterior, la disminución del gasto militar sería del $10 \%$ (Robayo, 2014).

\subsubsection{Escenario pesimista}

En este escenario se plantea la imposibilidad de llegar a un acuerdo entre el Gobierno nacional y las FARC, y, por lo tanto, el conflicto armado se intensificaría en el país, lo cual, con base en las teorías explicadas anteriormente, ocasionaría un empeoramiento de las condiciones económicas del país. En este escenario se proyecta una situación en la que los problemas sociales relacionados con el conflicto permanecerían iguales o incluso se agravarían. Fenómenos como el secuestro, la extorsión, los ataques hacia la población civil, a la infraestructura y a las fuerzas armadas generarían un debilitamiento de la economía nacional, lo que ocasionaría un bajo rendimiento de las variables de tipo financiero y de comercio internacional.

En el escenario pesimista están ubicados Sri Lanka y Perú. La balanza de bienes y servicios (\% del PIB) fue positiva para Sri Lanka en un $3 \%$ y negativa para Perú. El comercio, como \% del PIB, para Perú fue del 14\% y negativo para Sri Lanka, con el $21 \%$. Para la variable riesgo país, en el que se observó una estabilidad relativa con una variación mínima de 1 \% para Sri Lanka y de -4 \% para Perú, la calificación cambió, aumentando 0,5 puntos para Sri Lanka y disminuyendo 2 puntos para Perú.

Se cree que, para el caso colombiano en un escenario pesimista, las variables de balanza de bienes y servicios y la de comercio permanecerían iguales o tendrían una variación 
máxima del 1 al $3 \%$ para los próximos cinco años en el caso de que la guerra persista. Con respecto al riesgo país, este puede seguir igual o tener variaciones poco relevantes de manera positiva o negativa en 2 puntos, según la calificación que otorga The Economist.

Para las variables financieras se evidencian similitudes entre los comportamientos de los dos países guías. Por ejemplo, la IED bajó su nivel en promedio $30 \%$, esto quizás debido al miedo de los inversionistas a que este tipo de grupos armados resurjan. El gasto militar se redujo para Sri Lanka en $11 \%$ y en Perú en $18 \%$. El PIB de los dos países aumentó, siendo para Sri Lanka un $47 \%$ más alto con respecto a los cinco años anteriores al fin del conflicto, y fue un $18 \%$ más alto para Perú en las mismas condiciones. De igual manera, el crecimiento del PIB mejoró para los dos países, presentándose un promedio de $7 \%$ anual para Sri Lanka, es decir, un punto porcentual más alto, mientras que para Perú el promedio del crecimiento del PIB anual fue del $3.5 \%$, es decir, medio punto porcentual más alto comparado con los cuatro años anteriores al fin del conflicto ${ }^{1}$.

Con base en los datos anteriormente mencionados, se cree que, en un escenario pesimista para el caso colombiano, la IED podría bajar su nivel hasta un $20 \%$ respecto a los cinco años siguientes al rompimiento de las relaciones entre las partes negociadoras. Por otra parte, el porcentaje del PIB destinado al gasto militar tendría una reducción del $3 \%$ según lo analizado en los estudios de caso, debido al gran número de conflictos de orden social que se podrían presentar. La variable del PIB podría ser hasta un $15 \%$ más alto y el promedio del crecimiento del PIB anual podría llegar a ser un punto porcentual más alto, o sea, la economía colombiana crecería un $5 \%$ anual.

\subsubsection{Escenario neutro}

La situación que se plantea en este escenario consiste en la posibilidad de que se repita la situación presentada en el Gobierno de Andrés Pastrana, en el que se dio la ruptura de las negociaciones entre las FARC y el Gobierno nacional, lo cual significó seguir en la lucha armada, la continuidad del desplazamiento de la población rural y las extorsiones.

La IED aumentó un $33 \%$, además, el PIB también se incrementó, pero un $22 \%$; sin embargo, el gasto militar, aunque creció $3 \%$ como porcentaje del PIB, trajo consigo consecuencias sociales negativas. El flujo de comercio internacional fue negativo debido a que la balanza comercial de bienes y servicios (\% del PIB) disminuyó $10 \%$, no obstante, hay que tener en cuenta que se tuvo una balanza deficitaria durante todo el tiempo de estudio, que fueron once años. Además, el riesgo país presentó una disminución de 4.11 puntos y la variable de comercio (\% del PIB) presentó un pequeño aumento del $5 \%$.

1 No se tuvo en cuenta el crecimiento del PIB registrado en el primer año, es decir, 1994, el cual fue del $12.3 \%$ obtenido debido a las mejoras climáticas que se presentaron para ese año, lo que mejoró los sectores de manufactura, minería y agricultura, principalmente. (Cotler, 1995). 
Lo que se puede prever si se llegase a presentar una ruptura en este segundo intento de negociación, sería un aumento del gasto militar tras la reanudación de los ataques hacia las FARC, además de tener el apoyo de algunos países para el combate. En cuestiones económicas, la IED, la balanza comercial de bienes y servicios y el comercio tendrían una pequeña variación de entre el $3 \%$ y el $10 \%$ debido a que Colombia actualmente presenta políticas asertivas para la integración económica regional, políticas que han fortalecido al comercio internacional, pero el sector agro sí se vería afectado por la guerra interna y por los fenómenos climáticos.

Con base en los escenarios anteriormente planteados, se concluye que el mejor escenario es el optimista, dado el mayor beneficio que traería para los flujos financieros y de comercio internacional. A partir de ello, la imagen de Colombia en el extranjero mejoraría y sería un país más competitivo en temas de IED y turismo, lo que ayudaría al resto de variables económicas y financieras a crecer de manera paulatina a partir del cumplimiento de los acuerdos que se firmarían entre las partes.

\subsection{Validación grupo de expertos}

Con el fin de mitigar el riesgo de sesgos de información, se utilizó la validación con un grupo de expertos seleccionados a partir de una muestra de tipo no probabilístico. El grupo fue conformado por siete expertos en áreas de derecho, ciencia política, sociología, estudios latinoamericanos, ingeniería e historia, de universidades de Suiza, Inglaterra, Brasil y Colombia. Estos expertos están asociados con cargos públicos, investigación del posconflicto y de Latinoamérica, organizaciones no gubernamentales (ONG), aduanas y organizaciones intergubernamentales. Las entrevistas fueron realizadas entre diciembre de 2015 y enero de 2016. La estructura del cuestionario se compuso de siete ítems enfocados alrededor del punto de vista sobre la ocurrencia del escenario optimista. Algunas de las preguntas aplicadas fueron la siguientes: ¿qué tan probable cree usted que la balanza comercial de bienes y servicios de Colombia tenga un comportamiento superavitario en los próximos cinco años con un incremento de entre el $3 \%$ y el $6 \%$ ? ¿Cree usted que, en los próximos cinco años, si se firma el acuerdo de paz, el puntaje del riesgo país para Colombia aumente 4 puntos o más? Cada pregunta estuvo seguida por información de contexto sobre la variable cuestionada y lo ocurrido en los países guías de los escenarios correspondientes.

\subsubsection{Resultados}

Las respuestas de los expertos seleccionados se tabularon con base en la técnica Ábaco Régnier, mediante el uso de los colores del semáforo, en el que se refleja la opinión sobre la probabilidad de que se cumpla el comportamiento de las variables planteadas en el escenario mencionado (ver tabla 5). 
Tabla 5. Tabla de calificación de los expertos

\begin{tabular}{|l|l|l|l|l|l|l|l|}
\hline \multirow{2}{*}{\multicolumn{1}{|c|}{ VARIABLES }} & \multicolumn{7}{c|}{ EXPERTOS } \\
\cline { 2 - 8 } & 1 & 2 & 3 & 4 & 5 & 6 & 7 \\
\hline 1. Balanza comercial & & & & & & & \\
\hline 2. Comercio & & & & & & & \\
\hline 3. Riesgo Pais & & & & & & & \\
\hline 4. IED & & & & & & & \\
\hline 5. PIB & & & & & & & \\
\hline 6. Crecimiento del PIB & & & & & & & \\
\hline 7. Gasto militar & & & & & & & \\
\hline
\end{tabular}

\begin{tabular}{|c|l|}
\hline COLORES & SIGNIFICADO \\
\hline Verde & Muy probable \\
\hline Amarillo & Duda \\
\hline Rojo & Muy improbable \\
\hline Blanco & No respuesta \\
\hline
\end{tabular}

Fuente: Elaboración propia con base en información recopilada.

El grupo de expertos tuvo en común que la variable con menos probabilidad de ocurrencia sería la del gasto militar, en la cual se plantea una disminución de entre un 40 y un $50 \%$ en los próximos cinco años. Según las opiniones de los expertos, es poco probable que esta situación se obtenga en Colombia debido a que las FARC no es el único grupo al margen de la ley que existe en el país; además, el gasto militar no se puede reducir de tal manera, dado el número tan alto de integrantes que conforman la fuerza pública, al mismo tiempo que forman parte de la mesa negociadora.

La siguiente variable que no posee una probabilidad muy alta de que ocurra según los expertos es el aumento de 3 al $6 \%$ de la balanza de bienes y servicios. Los expertos argumentan que hay factores que pueden afectar más fuertemente esa variable, como el precio del dólar o la cotización actual del barril de petróleo, dada la dependencia económica del país de este producto.

Hay dudas acerca del aumento del crecimiento anual del PIB de 1 a 2 puntos porcentuales para los próximos cinco años, esto por los mismos factores mencionados anteriormente; además, los expertos explican que esta variable puede ser dinamizada no solo por el proceso de paz, sino por procesos políticos, de manera que la firma del acuerdo no sería un factor determinante.

El resto de variables - como el riesgo país, el comercio, la IED e incluso el PIB, en ese orden-tuvieron opiniones favorables acerca de los porcentajes propuestos en las preguntas de las entrevistas debido a que, el enfrentar esta problemática por vías diplomáticas, haría que la imagen internacional que tendría Colombia mejorara, convirtiéndola así en un buen destino de inversión, comercio y turismo ante el mundo, dado el aumento de percepción de seguridad.

En el mapa de la curva del conflicto que se muestra en la figura 11 se expone el ciclo de vida que el conflicto armado en Colombia ha tenido desde el Gobierno de Andrés 
Pastrana hasta el Gobierno del presidente Santos. Además, en este mismo diagrama se ubican tres grupos de expertos conformados según la posición que tiene cada uno de ellos frente al cambio de las variables en el escenario optimista propuesto.

El grupo 1, conformado por cuatro de los siete expertos, identificado con el círculo verde ubicado en la figura 11, posee una tendencia de apoyo hacia el escenario optimista, lo que implica que ellos consideran que la intensidad del conflicto interno en Colombia podría reducirse al firmar el acuerdo de paz con las FARC, siendo este uno de los tantos grupos al margen de la ley que existen en el país. Es por esto que la línea bajo el círculo verde indica que el escalamiento del conflicto proyectado a cinco años tendría una reducción de intensidad y que las fuerzas armadas de Colombia renovarían sus funciones, centrándolas hacia otros grupos al margen de la ley, pero sin reducir significativamente el presupuesto hacia la defensa. Es importante destacar que este grupo considera que, si se logra un posconflicto estable y se mantiene una confianza en el Gobierno nacional, se tendrían que brindar las garantías para ello.

El grupo 2, compuesto por uno de los siete expertos, identificado con el círculo amarillo, expresa una postura de duda frente a las implicaciones que se podrían presentar en la economía colombiana tras una firma de los acuerdos de paz con las FARC. Esta incertidumbre surge tras una falta de información por parte de los negociadores sobre los avances de los acuerdos.

El grupo 3, conformado por dos de los siete expertos, identificado con el círculo rojo, tiene una tendencia pesimista frente al comportamiento del conflicto en los próximos cinco años, debido a que ellos aseguran que si no se llegasen a dar los debidos planes jurídicos y económicos por parte del Estado, que aseguren un posconflicto estable, la intensidad del conflicto podría llegar a aumentar, es por esto que se ubican en un punto de la figura en la cual el conflicto podría llegar a escalar, lo que implicaría afectaciones directas al PIB debido a que sectores, tan importantes en la economía colombiana, como el agro y la minería, volverían a ser vulnerables. Además, aseguran que otros factores externos - como el precio de las materias primas, el precio del dólar y factores climáticos- tendrían un impacto mayor en el comportamiento de las variables que el mismo acuerdo firmado con las FARC.

En conclusión, se observa la división que existe entre la población colombiana sobre el apoyo o rechazo al acuerdo que se puede firmar entre las FARC y el Gobierno nacional, en parte por falta de información sobre las negociaciones, los planes hacia el futuro sobre la economía y la nueva reorganización social que se enfrentará, principalmente en las poblaciones más afectadas por la presencia de las FARC. Por otra parte, los expertos coinciden en que el acuerdo de paz no es el único factor que determinará el comportamiento de las variables de los flujos financieros y de comercio internacional en los próximos cinco años. 


\section{CIFEE 27}

ISSN: 0124-3551 / Año 17, No 27 / julio-diciembre / pp. 23-54

Figura 11. Ubicación de los expertos en la curva de conflicto

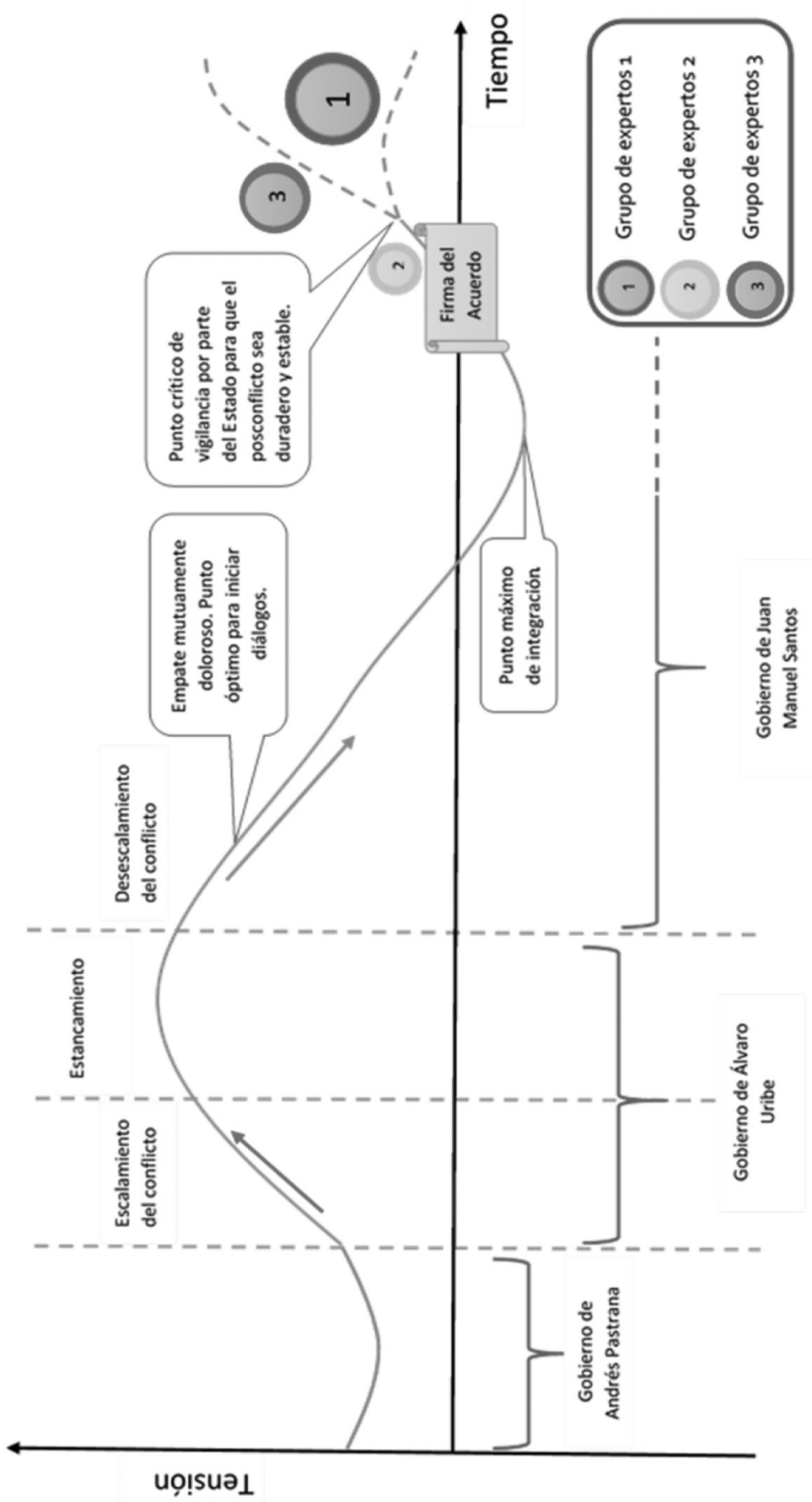

Fuente: Elaboración propia con base a USIP (2008). 


\section{Conclusiones}

El escenario que aporta mayor beneficio a los flujos financieros y de comercio internacional es el escenario optimista, en el cual se daría un comportamiento positivo en los próximos cinco años, escenario en el que la balanza de bienes y servicios tendría un incremento de entre el 3 y el $6 \%$; la variable comercio sería entre 10 y $15 \%$ mayor; el riesgo país incrementaría 4 puntos o más; la IED aumentaría entre el 40 y 50 \%; el PIB crecería entre el 25 y $35 \%$; el crecimiento del PIB anual sería 1 o 2 puntos porcentuales más alto al registrado actualmente; y respecto al gasto militar, la disminución no sería mayor al $10 \%$.

A pesar de los comportamientos positivos mostrados en los países guía que enfrentaron el escenario optimista, no se considera que la firma del acuerdo de paz con las FARC sea el único determinante del comportamiento futuro de la economía, por el contrario, los inversionistas y las empresas deberían tener en cuenta otros factores de tipo cambiario, tributario, climático, fluctuación de los precios de las materias primas, productividad de las empresas o cese de actividades por diferentes grupos económicos, entre otros. Por esta razón, es necesario aclarar que las variables no incrementarían drásticamente debido a la firma del acuerdo.

Es importante resaltar que el conflicto interno afecta a todos los agentes económicos, ya sea de forma directa o indirecta, pero si se llegase a firmar el acuerdo de paz de forma exitosa, los sectores más beneficiados serían el agropecuario, el minero y las PYMES que ejercen su ejercicio en zonas de conflicto, sectores que dejarían de ser víctimas de extorsiones o atentados.

\section{Referencias}

Álvarez, E. y Pardo, T. P. (2002). Guatemala's peace process: Context, analysis and evaluatión. Londres: Conciliation Resources. Recuperado de goo.gl/f0q9da

Arias, M. A., Camacho, A., Ibáñez, A. M., Mejía, D. y Rodríguez, C. (2014). Costos económicos del conflicto en Colombia. ¿Cómo construir un posconflicto sostenible? Bogotá: Universidad de los Andes. Recuperado de goo.gl/urOfMM

Banco Mundial. (2015). Comercio (\% del PIB). Datos sobre las cuentas nacionales del Banco Mundial y archivos de datos sobre cuentas nacionales de la OCDE. Recuperado de http:// datos.bancomundial.org/indicador/NE.TRD.GNFS.ZS

Bello-Montes, C. (2014). Desafíos y estado futuro de la convivencia en Colombia al 2025. Revista Criminalidad, 56(2), 319-332. Recuperado de http://www.scielo.org.co/ pdf/crim/v56n2/v56n2a10.pdf 
ISSN: 0124-3551 / Año 17, No 27 / julio-diciembre / pp. 23-54

Brahimi, L. (2007). State building in crisis and post-conflict countries. Viena, Austria: SecretaryGeneral of the United Nations. Recuperado de goo.gl/BEcFMQ

Brauer, J., \& Marlin, J. T. (2009). Defining peace industries and calculating the potential size of a peace gross world product by country and by economic sector. Sydney, Australia: IEP Publications. Recuperado de goo.gl/O7XJbV

Caston, E. (2013). Civil War in Perú (1980-2000). Recuperado de goo.gl/8ayotO

Centro Nacional de Memoria Histórica (CNMH). (2013). Una guerra prolongada y degradada. Dimensiones y modalidades de violencia. En Autor, iBasta ya! Colombia: Memorias de guerra y dignidad. Bogotá D. C.: Imprenta Nacional.

Collier, P. (1999). On the economic consequences of civil war. En A. Banerjee y J. Forder, Oxford Economic Papers 51 (pp. 168-183). Oxford, Reino Unido: Oxford University Press.

Correa, J. D. (2011). Examinando el futuro: Metodología propuesta para el estudio prospectivo y estratégico de la Universidad de Cundinamarca (2010-2019). Esquemas Pedagógicos, 9, 7-10. Recuperado de goo.gl/pHYfwL

Cotler, J. (1995). Perú 1964-1994. Economía, sociedad y política. Lima: IEP Ediciones.

DANE. (2015). Series de población. Recuperado de http://www.dane.gov.co/index.php/ estadisticas-por-tema/demografia-y-poblacion/series-de-poblacion

Escárzaga, F., Llaque, J. A. y Chamorro, A. (2002). Migración, guerra interna e identidad andina en Perú. Política y Cultura, 18, 278-298. Recuperado de http://www. redalyc.org/articulo.oa?id=26701813

Fedesarrollo. (2014). El impacto de un eventual fin del conficto armado sobre el mercado laboral colombiano. Bogotá D.C.: Digitalware Ediciones.

Fisas, V. (2010). Procesos de paz comparados. Quaderns De Construcció De Pau, 14, 5-9. Recuperado de goo.gl/WHtCG6

Gregory, K. (2009). Shining Path, Tupac Amaru (Peru, leftists). Recuperado de http://www. cfr.org/peru/shining-path-tupac-amaru-peru-leftists/p9276

Guaresma, J. G., \& Reitschuler, G. (2006). Guns or butter? Revisited: Robustness and nonlinearity issues in the defense-growth nexus. Scottish Fournal of Political Economy, $53(4), 523-541$. 
Harrison, T. (2010). The new guns versus butter debate. Washington D.C.: The Center for Strategic and Budgetary Assessments Press.

Herbst, J. (1990). War and the State in Africa. Princeton, New Jersey, EE. UU.: Princeton University Press.

Intriligator, M. D. (1996). The concept of a peace dividend. En EOLSS, Economics Of Peace And Security (pp. 72-79). Nueva York: EOLSS. Recuperado de goo.gl/cKNOZb

Justino, P. (2010). War and poverty. En MICROCON, MICROCON Research Working Paper 32 (pp. 3-5). Brighton, Reino Unido: MICROCON Research.

Keynes, J. M. (1919). The economic consequences of the peace. Nueva York: Harcourt, Brace and Howe, Inc.

Knight, M., Loayza, N. y Villanueva, D. (1996). The peace dividend: Military spending cuts and economic growth. IMF Staff Papers, 43(1), 1-37. Recuperado de goo.gl/ SWqz5r

Kugiel, P. (2009). El fin de la guerra en Sri Lanka. Aspectos internacionales. Boletín del PISM, 44(44). Recuperado de goo.gl/GcxSdW

Mayorga, R., Cerén, S. S., Nikken, P., Horst, E. T. y Galindo, D. E. (2015). El Salvador, de la guerra civil a la paz negociada. San Salvador: Ministerio de Relaciones Exteriores de El Salvador, Dirección General de Cultura. Recuperado de https://issuu.com/ cancilleriasv/docs/delaguerraalapaz

Mesa de Conversaciones. (2012). Acuerdo general para la terminación del conflicto y la construcción de una paz estable y duradera. Recuperado de goo.gl/EpXEhN

Mojica, F. J. (2005). La construcción del futuro. Concepto y modelo de prospectiva estratégica, territorial y tecnológica. Bogotá: Universidad Externado de Colombia.

- (2008). Dos modelos de la escuela voluntarista de prospectiva estratégica. Recuperado de http://www.franciscomojica.com/articulos/modprosp.pdf

Oxfam International. (2003). Angola: Construyendo la paz. Ponencia presentada en el Congreso Internacional de Estudios Africanos "África Camina". Recuperado de goo.gl/SPOhF3

Paz, L. M. (2010). Sri Lanka. Historia de un conflicto. Recuperado de http:/ / www.accionculturalcristiana.org/html/revista/r75/75sril.pdf 
ISSN: 0124-3551 / Año 17, No 27 / julio-diciembre / pp. 23-54

Rawat, A. (2012). Civil war in Sri Lanka. IAAS. The Nereslette, 59. Recuperado de http:// www.iias.nl/sites/default/files/IIAS_NL59_1415.pdf

Ribera, R. (1994). El Salvador: La negociación del acuerdo de paz. ¿Un modelo para el mundo? Realidad. Revista de Ciencias Sociales y Humanidades, 37, 89-134. Recuperado de goo.gl/tajs2f

Robayo, L. (20 de abril de 2014). Pie de fuerza aumentó en 42 mil efectivos. El Nuevo Siglo. Recuperado de goo.gl/Pp0WHb

Schippa, C. (2010). El valor de la paz para la economía. En M. Prandi y J. M. Lozano (eds.), La RSE en contextos de conflicto y postconflicto: de la gestión del riesgo a la creación de valor (pp. 73-80). Barcelona: Escola de Cultura de Pau y ESADE. Recuperado de http:// escolapau.uab.cat/img/programas/derecho/webRSE.pdf

Tagle, S. D., Checa, A. G., \& Sala, N. P. (2008). Riesgo país en mercados emergentes. Barcelona: IDEG Escuela de Estudios Superiores, Universitat Pompeu Fabra Press. Recuperado de http://docplayer.es/4355365-Riesgo-pais-en-mercados-emergentes.html

The Economist. Intelligence Unit. (2014). Country Report. Comprehensive political and economic coverage for 197 markets. Recuperado de goo.gl/4N09Rp

Tzifakis, N. (s. f.). Post-Conflict Economic Reconstruction. En Encyclopedia Princetoniensis. The Princeton Encyclopedia of Self-Determination. Recuperado de https://pesd.princeton. edu/?q=node $/ 260$

Ugarriza, J. E. (2013). La dimensión política del postconflicto: Discusiones conceptuales y avances empíricos. Colombia Internacional, 77, 141-176. Recuperado de http://www. redalyc.org/articulo.oa?id=81226288006

United States Institute of Peace - USIP. (2008). Ánalisis de conflictos. Washington D. C.: Autor.

Universidad del Rosario. (2015). Experimento sobre reconciliación política en Colombia. Recuperado de goo.gl/sUCznu

Vela, J. E. (2011). El indicador riesgo país EMBI (Emerging Markets Bond Index): Las tasas de interés y su incidencia en el mercado bursátil de Colombia en el periodo 2002-2009 (Trabajo de tesis). Universidad de La Salle, Bogotá. Recuperado de goo.gl/PwSlwI

Villegas, J. B. y Cortez, D. V. (2011). El uso del método MICMACy MACTOR análisis prospectivo en un área operativa para la búsqueda de la excelencia operativa a través del Lean Manufacturing. Ciudad de México: UANL Editorial. Recuperado de http://www.web.facpya.uanl. $\mathrm{mx} / \mathrm{rev}$ _in/Revistas/8.2/A6.pdf 